Manuscript received January 25, 2018; accepted for publication March 13, 2018; published online April 26, 2018.

1 Department of Civil, Environmental, and Architectural Engineering, University of Kansas, 1530 W 15th St., Lawrence, KS 66045, USA, (1) https://orcid.org/ 0000-0003-1383-7750 (M.N.)

2 Gannett Fleming, Inc., 5 Eves Dr., Suite 200, Marlton, NJ 08053, USA

${ }^{3}$ Department of Civil, Environmental, and Architectural Engineering, University of Kansas, 1530 W 15th St., Lawrence, KS 66045, USA (Corresponding author), e-mail: jiehan@ku.edu, (1) https://orcid.org/0000-00033137-733X

${ }^{4}$ Hart Crowser, Inc., 7 Waterfront Plaza, 500 Ala Moana Blvd., Honolulu, HI 96813, USA
Madan Neupane, ${ }^{1,2}$ Robert L. Parsons, ${ }^{1}$ Jie Han, ${ }^{3}$ David A. Parr, ${ }^{1}$ and James A. Jacobe ${ }^{4}$

\section{Evaluation of Soil Saver Walls on Aquatic Organism Passage Through Box Culverts}

\section{Reference}

Neupane, M., Parsons, R. L., Han, J., Parr, D. A., and Jacobe, J. A., "Evaluation of Soil Saver Walls on Aquatic Organism Passage Through Box Culverts," Journal of Testing and Evaluation, Vol. 46, No. 4, 2018, pp. 1313-1320, https://doi.org/10.1520/JTE20180055. ISSN 0090-3973

\section{ABSTRACT}

Reinforced concrete box culverts are designed to provide hydraulic conveyance at peak stream discharge in a cost-effective manner; however, these structures can promote headcutting. Many state departments of transportation construct soil saver walls or similar structures on the upstream of box culverts to prevent headcutting. These walls act as a drop inlet and may hinder free movement of aquatic organisms. The potential impact on aquatic organism passage has resulted in regulatory pressure to develop alternatives or modifications to the traditional soil saver wall design. This article contains the results of an analysis of the potential impact of box culverts with solid soil saver walls on aquatic organism passage. The results of a survey of thirty states and fifteen field sites on the current state-of-practice for box culverts, and flume tests using model box culverts with a solid soil saver wall and with modified design to promote aquatic passage are presented. Modifications to the soil saver wall design are recommended based on the results of the survey of states, field surveys, and flume testing.

\section{Keywords}

soil saver wall, aquatic organism passage, headcutting, upstream erosion, box culvert, scour

\section{Introduction}

Design considerations for reinforced concrete box (RCB) culverts have traditionally included traffic capacity and safety, hydraulic conveyance for design stream discharge, and low initial cost in construction and maintenance as compared with other crossing structures, such as single- or multiple-span bridges [1]. Box culverts are typically narrower than the corresponding channel width. This situation creates a channel constriction that, along with smooth roughness of the box, causes higher flow velocities. This phenomenon can lead to upstream channel bed incisions and downstream bed scouring. Moreover, RCB culverts can impede aquatic organism passage (AOP) and hinder the ability of organisms to move freely throughout their ecosystem in order to complete their life cycles [2]. This obstruction occurs when passage conditions exceed the ability of the aquatic organisms to overcome the inlet or outlet drop height, excess flow velocity or turbulence, or behavioral barriers [3,4]. A study in Midwest showed that there were 
3.3 times less likely to move fish through low-water crossings including box culverts than through natural riffles [5]. RCB culverts can present a strong barrier to upstream migration of fish and other aquatic organisms and may cut off access to spawning, feeding and wintering areas. In some cases, these barriers can force a small subset of a species to survive independently in a small stretch of stream. These smaller, more isolated populations are more likely to die of chance events in short term [6]. Genetic homogeneity and natural disturbances are likely to destroy larger population. In a long run, the stream obstruction may deteriorate the hydrologically diverse and dynamic ecosystem of stream completely [7]. Both short and long-term cases significantly disturb the surrounding ecosystem. To facilitate AOP, pipe (circular, elliptical, or arched with a bottom) culverts are generally set below the streambed level. Bottomless (three sided or arched) culverts promote AOP better than RCB and pipe culverts because they preserve a portion of the natural channel [8]. Because bottomless culverts are AOP friendly, many researchers recommended bottomless arch culverts as ecological bridges instead of pipe and box culverts. However, the RCB culverts are more popular because of their simple construction methodology and easy installation in medium size stream crossing.

Grade control structures are the common practice to minimize the upstream erosion. The structures include check dam, low head weir, and barrier. Several experimental studies and numerical modeling have been carried out to investigate the effects of these structures on sediment and erosion control as well as upstream scouring. These studies ranged from very large scale to very small scale.

Many departments of transportation (DOTs) have used a grade control structure, referred to in this article as a soil saver wall (SSW), at the upstream end of box culverts where the potential for headcutting is a concern. The SSW is a concrete structure spanning the width of the channel at the end of the upstream culvert apron and is designed to retain the streambed material to prevent headcutting [9]. Fig. 1 shows a typical double barrel box culvert with a SSW. Box culverts with SSWs are often recessed below the streambed, which makes it possible to reduce the grade of the box and the severity of downstream scouring. SSWs combined with concrete wing walls create a drop inlet to the box culvert and have been effective at preventing headcutting in streams. SSW structures include vertical concrete walls, gabion walls used as upstream weirs, and stone masonry upstream walls. They are simple and cost-effective structures.

SSW can create a severe barrier to the migration of aquatic organisms for the medium to low-flow condition because of the vertical drop associated with the SSW. For this reason, state regulatory agencies in Kansas and other states have requested that alternatives to the traditional SSW be used to facilitate AOP. The alternatives currently being considered, such as bridges, will be significantly more expensive than SSWs. There are currently more than 190 box culverts with SSWs in Kansas and many similar
FIG. 1 Typical box culvert inlet structures with solid SSW.

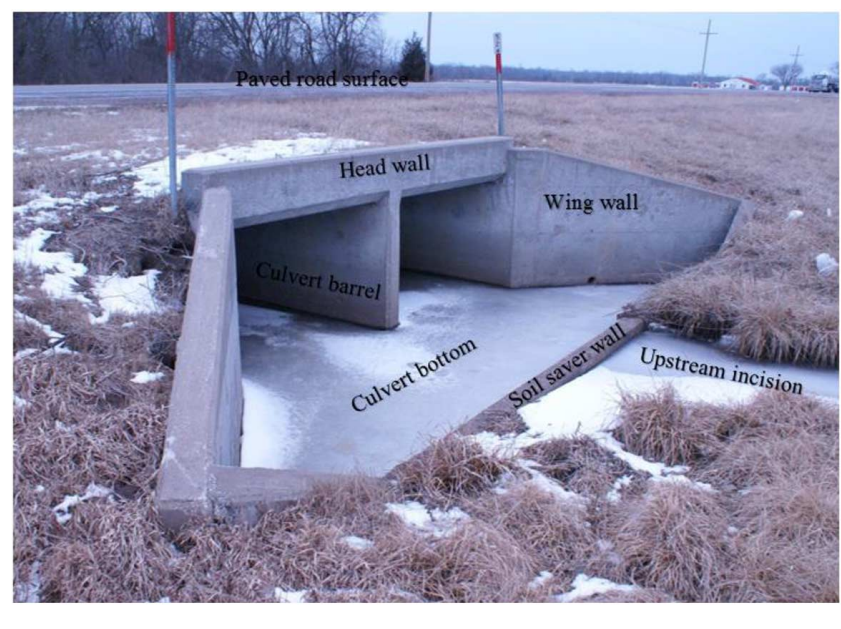

structures throughout the United States. Development of SSW modifications that will make possible the construction of AOP friendly new and replacement culverts can provide substantial savings to DOTs by continued use of box culverts, while avoiding the need to construct more expensive cross-drainage structures.

An engineered culvert should meet the criteria of appropriate hydraulic capacity, structural integrity, and wildlife habitat continuity [10]. To facilitate AOP, the California State Department of Fish and Game recommends the culvert be designed to meet the criteria of "Active Channel Design Option," "Stream Simulation Design Option," or "Hydraulic Design Option [11]." The hydraulic design option prioritizes the swimming abilities of target species and the age class of particular types of aquatic life. Determination of high and low design flows for targeted AOP, water velocity, and water depth are the guiding parameters for this option [12]. Culverts may create one or more types of barriers in the river. The primary potential barrier is high flow velocity, as well as the creation of jumps and eddies. Other barriers include exhaustion and behavior barriers, downstream scouring and upstream progressive channel incision [13], as well as isolation of the floodplains from the main channel and forcing the flood flows through the culvert barrel [14]. The Washington Department of Fish and Wildlife emphasized the need to consider various concerns while designing AOP-friendly culverts, which may dictate the siting, sizing, and design of culverts for AOP improvement [15]. These concerns include (a) direct habitat loss, (b) water quality degradation, (c) upstream and downstream channel impacts, (d) ecological connectivity, (e) construction impact on river channels, and (f) probable future impact on the channel because of the risk of culvert failure. Inclusion of an SSW at upstream of the culvert adds a vertical drop that can block the use of the upper watershed and reduce access to spawning habitat.

The Natural Resources Conservation Service developed flow velocity criteria for culverts based on the ability of target 
organisms to migrate upstream and downstream [16]. Design of stream crossings to maintain continuity of flow with manageable flow velocity in accordance with the swimming and leaping capabilities and physiological requirements of target species (or a similar species with comparable swimming abilities) is fundamental to providing target species with a healthy environment [16]. Several techniques have been developed to improve the fish passing capacity of culverts. These techniques include the offset baffle system [17], the spoiler baffle system [18], the side baffles system [19], the fish weirs and fish baffles system [20], and the slotted weir culvert system [21]. However, these are all modifications to the bottom of the box culverts and these methods do not address the barriers presented by the SSW.

\section{Regulatory Issues}

Over the last few decades, increased awareness of the importance of AOP has made it a critical design parameter for culverts in many states. In the state of Kansas, the Kansas Department of Wildlife Parks and Tourism (KDWPT) has implemented protective regulations for these critical habitats of wildlife species that require obtaining an "Action Permit" if a newly constructed culvert has the potential to cause destruction, modification, or curtailment of threatened and endangered species' habitat or range of habitat [22]. In addition to this permit, the Clean Water Act (CWA) Section 404 permit, containing "Nationwide Permit 14 - Linear Transportation Projects" and "Nationwide Permit 3 - Maintenance" and issued by the United State Army Corps of Engineers, requires that AOP be considered in the design of the culvert structure [23]. Based on the recommendations provided by Haslouer et al. [24], KDWPT developed a list of endangered species, threatened species, and species in need of conservation and updates this list regularly [25]. In Kansas, many of these threatened and endangered species are minnows or minnow-size fish in streams of a size where box culverts are commonly used [26], and a minimal continuous flow is sufficient for target species' passage.

\section{Box Culvert Practices}

Thirty states responded to a survey from the authors regarding their experience with box culverts and any regulatory issues related to AOP at box culverts. The questions asked in this survey were:

Are the states experiencing headcutting at upstream of box culverts?

What methods do states use to remedy or prevent headcutting at upstream of box culverts?

What methods, if any, do the states use for AOP through box culverts?

What was the level of regulatory concern in these states about AOP?
This survey revealed that several of these states did not install measures to prevent headcutting for a variety of reasons. Some states did not use headcutting prevention measures specifically to avoid hindrance of AOP in or around their box culverts, others were due to the natural rocky settings that made the need to prevent headcutting moot, and still others were adjusting their stream design philosophy to more closely follow state-of-the-art stream simulation from the Federal Highway Administration [4]. Of the states surveyed, the Alabama, Arizona, California, Illinois, Iowa, Maine, South Dakota, Maryland, Michigan, Washington, Mississippi, Nebraska, Oklahoma, Texas, West Virginia, and Wyoming DOTs have experienced problems with severe headcutting. One state has been using a low-height, soil-saver-wall-like structure before the inlet and hence may have some concerns from regulatory bodies. The Arizona DOT has been using one type of SSW and has not faced any regulatory concerns because of the provision for a small drop inlet with a small cutoff wall for low-flow. California has been adopting a stream simulation design approach and using rock weirs and baffles but is seeking better AOP simulation because of regulatory concerns. The Illinois DOT has been installing small cutoff walls, and the regulatory concern is not significant. The Iowa, Maine, and South Dakota DOTs have been installing drop inlets or countersunk sediment sills, with or without notches or drain holes, to prevent upstream headcutting, and they do not have any regulatory concerns because regulatory agencies are actively involved in planning phase. The Maryland DOT generally uses upstream sloping riprap and fish ladders on box culverts and regulatory agencies are actively assisting them with AOPfriendly culvert construction recommendations. Mississippi does not implement any type of incision preventive measures and faces some regulatory concerns because of headcutting. Four states have been using SSW structures and have not experienced regulatory problems.

Other state DOTs, including Alaska, Arkansas, North Dakota, Ohio, Connecticut, Florida, Delaware, Louisiana, Vermont, Virginia, Missouri, New Hampshire, Pennsylvania, South Carolina, and Virginia, have not faced significant problems of headcutting because these states have been using different types of SSW-like structures. These structures include V-notched concrete walls, small cutoff walls including upstream riprap, log vanes, rock or gabion weirs, and similar structures. Most of these states have been encouraged by regulators to improve their box culverts for AOP. Only two of the states surveyed have not faced any types of regulatory concerns for their traditional box culverts.

\section{Field Study}

Fifteen field surveys of existing box culverts with SSW were made in eastern Kansas to evaluate their effectiveness for preventing headcutting and to assess the potential impact of modifications to these SSW for AOP. The existing sites showed that all 
SSWs were preventing upstream incision for locations where there was no defined upstream channel. For the streams with a defined upstream channel, some sites had very minor headcutting just at upstream from the SSW unless they were rip-rapped, in which case they had none. Only 2 of the 15 box culverts visited appeared to be in a perennial stream. The remaining culverts were either in a channel that was completely dry upstream or downstream of the culvert, or both, or were in a constructed storm drainage channel. These SSWs varied in height from approximately six inches to three feet.

The finding of this field survey supports the viability of SSW in the region, as most of them are used in ephemeral channels or where there is no defined channel. This survey showed that there was little to no headcutting at upstream of the SSW, and it is concluded that SSWs are very effective for the prevention of headcutting.

\section{Flume Study for Proposed Modifications of SSW}

A flume study was performed in the laboratory to compare the headcutting patterns that form upstream of a solid SSW and evaluate the walls modified with added notches to promote AOP. This evaluation was to determine if these modifications would compromise the grade control function of the SSW. This flume study included testing of a solid SSW and walls with a square notch and a V-notch.
A model culvert of 1:24 scale was proposed for flume testing. The prototype square sectional area of the culvert was $3 \mathrm{~m} \times 3 \mathrm{~m}$ with aprons of $3 \mathrm{~m}$ in length. The box culvert scale model was constructed out of marine-grade 12-mm-thick plywood and coated with waterproof paint as shown in Fig. 2. A model of an SSW with a prototype height of $0.61 \mathrm{~m}$ and a length of $9.75 \mathrm{~m}$ (model height of $51 \mathrm{~mm}$ and length of $405 \mathrm{~mm}$ ) was added to the front of the culvert at the edge of the inlet apron.

The bed material was uniformly distributed fine to medium size laboratory grade sand. This sand was selected because it could reach a level bed condition quickly for different discharges on the flume. The coefficient of curvature $\left(C_{c}\right)$, the coefficient of uniformity $\left(C_{u}\right)$, the mean particle size $\left(D_{50}\right)$, the maximum particle size, and the specific gravity $(G)$ of the material were $0.82,2.8$, $0.41 \mathrm{~mm}, 1 \mathrm{~mm}$, and 2.67, respectively. The sand did not have any fine ( $<75$ micron) content. The sand was uniformly placed into the test flume (upstream and downstream of the model culvert) with a lift thickness of $50 \mathrm{~mm}$ before the test was run. Aggregate was used as riprap at the outlet of the culvert to prevent erosion of the bed materials.

The capacity of this model culvert is guided by the either the upstream control at the SSW (Eq 1) or the inlet control of the culvert itself (Eq 2) [27]. The lower discharge resulting from these two equations for a fixed energy level controls the culvert discharge.

$$
q_{s s}=\frac{Q}{B} \Rightarrow y_{c, s s}=\left(\frac{q_{s s}^{2}}{g}\right)^{1 / 3} \Rightarrow E_{c, s s}=\left(1.5+\frac{K}{2}\right) * y_{c, s s}
$$

\section{FIG. 2}

Prototype culvert geometries (Modeled at 1:24 scale): (a) no SSW, (b) with a solid SSW, (c) with a square notch and a slope ramp SSW and (d) with a V-notch SSW.

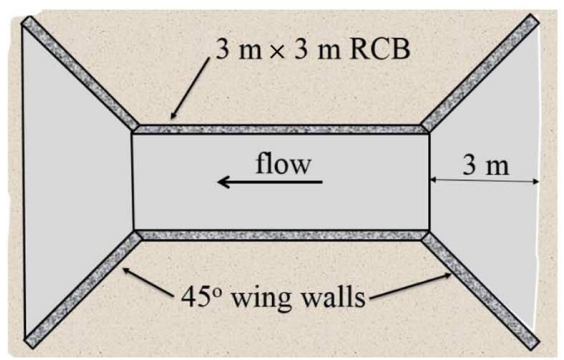

(a)

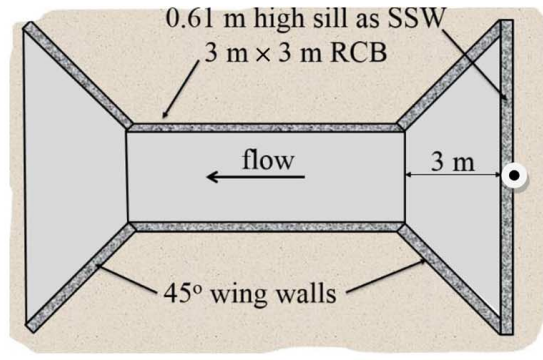

(b)

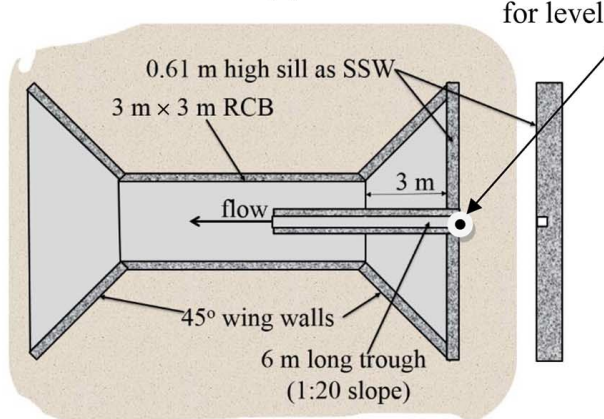

(c)

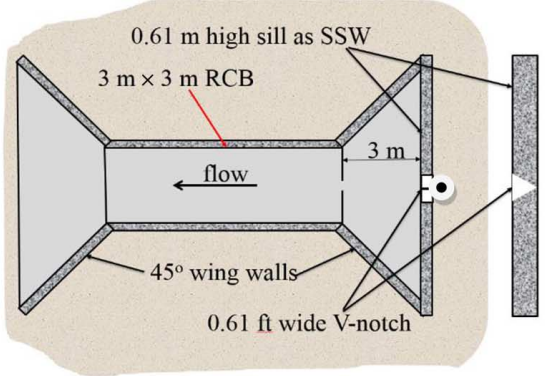

(d) 
FIG. 3

Culvert inlet with upstream scour due to the solid SSW.
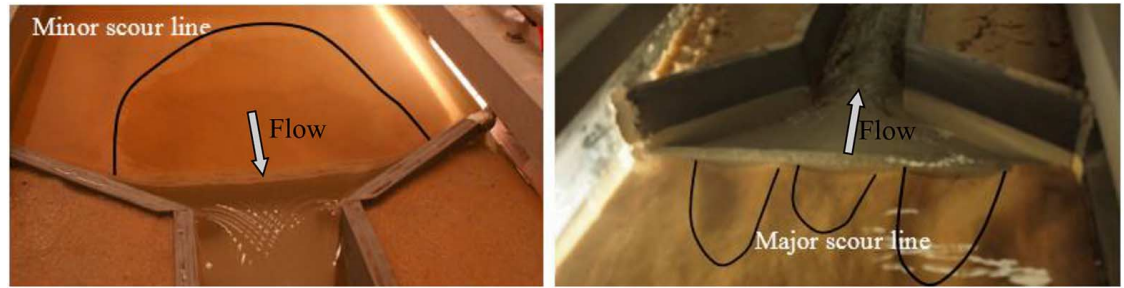

$$
q_{c v}=\frac{Q}{b} \Rightarrow y_{c, c v}=\left(\frac{q_{c v}^{2}}{g}\right)^{1 / 3} \Rightarrow E_{c, c v}=\left(1.5+\frac{K}{2}\right) * y_{c, c v}
$$

where $Q=$ flume discharge $\left(\mathrm{mm}^{3} / \mathrm{s}\right), B=$ length of the SSW $(\mathrm{mm}), q_{s s}=$ specific discharge at SSW $\left(\mathrm{mm}^{2} / \mathrm{s}\right), y_{c, s s}=$ critical height at SSW $(\mathrm{mm}), g=$ gravitational acceleration $\left(\mathrm{mm} / \mathrm{s}^{2}\right)$, $E_{c, s s}=$ specific energy at SSW $(\mathrm{mm}), K=$ inlet coefficient, $b=$ width of the culvert $(\mathrm{mm}), q_{c v}=$ specific discharge at culvert $\left(\mathrm{mm}^{2} / \mathrm{s}\right), y_{c, c v}=$ critical height at culvert inlet $(\mathrm{mm})$, and $E_{c, c v}=$ specific energy at culvert inlet $(\mathrm{mm})$.

Two alternative soil saver models were studied without changing the hydraulic design criteria of the culvert as presented in Fig. $\mathbf{2 c}$ and $\mathbf{d}$ and described as follows:

(a) SSW with a square notch of $305 \mathrm{~mm} \times 305 \mathrm{~mm}$ with a $6.1 \mathrm{~m}$ ramp channel, and

(b) SSW with a 120-degree V-notch of $610 \mathrm{~mm}$ (full depth notch).

\section{Flume Test Results}

Constant discharge was passed through the 405-mm-wide flume. The discharge was permitted to flow for several hours to develop a stabilized sand bed. This model was set in a 51- to 76-mm-thick fine-to-medium grain sand bed. These tests were conducted at different discharges for each type of SSW. The flume bed level (FBL), sand bed level (SBL), and water surface level (WSL) at upstream of SSW were recorded at the center of the flume. Photographs were taken to analyze the upstream incision that developed because of an SSW and a modified SSW. Pictures clearly showed two types of upstream souring. The first was deeper local scouring that extended a small distance from the SSW. The second consisted of shallow scouring that covered a much larger area. The first and second types of scouring are referred to as major and minor scouring in this article.

\section{CULVERT WITH SOLID SSW}

Two different amounts of discharge were passed through the flume with the model solid SSW culvert. Minor headutting developed to an extent. The major headcutting was deeper at two sides of the culvert inlet and less pronounced in the middle part of the channel. As the discharge increased, the depth and extent of headcutting increased. Fig. 3 shows the headcutting patterns at upstream of the solid SSW. Fig. 4 presents the upstream flow and the bed profiles at low-flow and high-flow conditions for the model culvert with the solid SSW.

At a low-flow rate, the average flow depth was $30 \mathrm{~mm}$, and the flow velocity was $195 \mathrm{~mm} / \mathrm{s}$, which yielded $0.002 \mathrm{~m}^{3} / \mathrm{s}$ discharge. At a high-flow rate, the average depth was $63 \mathrm{~mm}$, and the flow velocity was $201 \mathrm{~mm} / \mathrm{s}$, which yielded $0.004 \mathrm{~m}^{3} / \mathrm{s}$ discharge. Major headcutting at the middle portion of the SSW was negligible at low-flow, while the sides experienced a considerable amount of headcutting. The minor headcutting pattern developed to a small extent under

FIG. 4 Model upstream flow and bed profile of solid SSW: (a) low-flow and (b) high-flow.

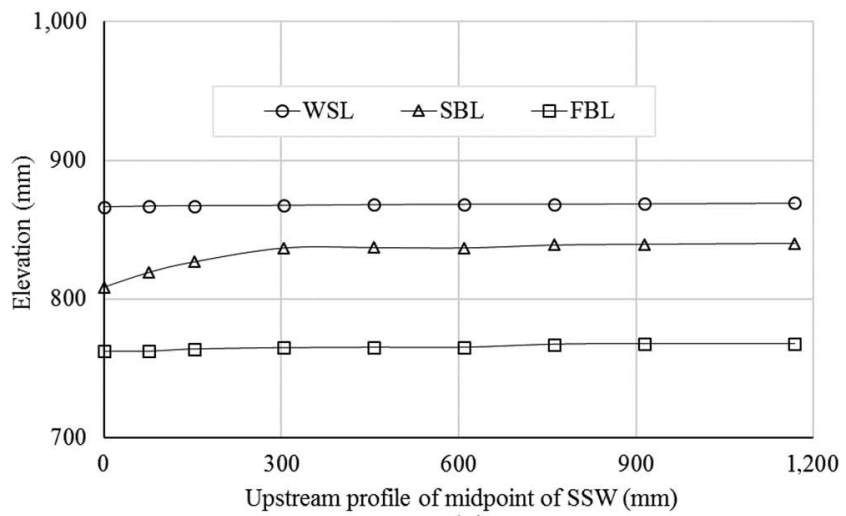

(a)

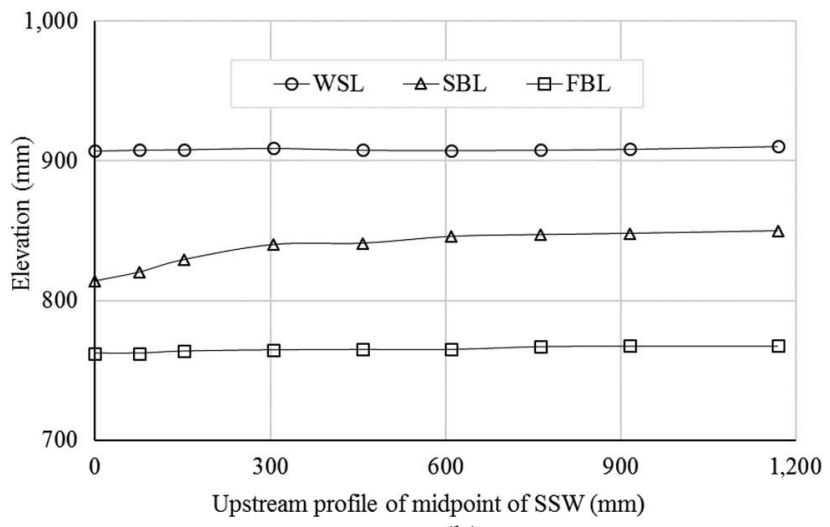

(b) 
the low-flow condition compared to that under the high-flow condition. The extent of the minor elliptical headcutting was about $280 \mathrm{~mm}$ under low-flow at the center of the flume and about $510 \mathrm{~mm}$ under high-flow. However, the slope of the headcutting for the low-flow was steep as compared to the high-flow.

\section{CULVERT WITH SQUARE NOTCH SSW WITH TRANSITION RAMP}

Tests were conducted under low-flow and high-flow conditions on the SSW with a square notch and a transition ramp. The results under low-flow and high-flow were similar to those for the solid SSW. The minor headcutting resembled a shortened semi-ellipse. The major headcutting immediately at upstream of the square notch SSW generated a slightly different shape from the solid SSW. The major headcutting had two deeper scour pockets at the sides and one shallow scour directly at upstream of the notch. A significant deposit was seen just at upstream of the minor scour line boundary. It was observed that the major headcutting depth was slightly greater in the middle of the flume and almost the same as those at the sides when compared with the solid SSW. This additional scour in the middle was caused by the notch. Fig. 5 shows the scour patterns for the SSW with a transition ramp. Fig. 6 presents the upstream flow and the bed profile at low-flow and high-flow conditions for the culvert with a square notch SSW.

As shown in Fig. 6a, at low-flow, the average flow depth was $30 \mathrm{~mm}$ and the flow velocity was $320 \mathrm{~mm} / \mathrm{s}$, which yielded a discharge of $0.003 \mathrm{~m}^{3} / \mathrm{s}$. At high-flow as shown in Fig. $\mathbf{6 b}$, the average flow depth was $70 \mathrm{~mm}$, and the flow velocity was $330 \mathrm{~mm} / \mathrm{s}$, which yielded a discharge of $0.007 \mathrm{~m}^{3} / \mathrm{s}$. The extent of the elliptical headcutting was about $230 \mathrm{~mm}$ at low-flow and about $356 \mathrm{~mm}$ at high-flow. The slope of the headcutting under lowflow conditions was steeper than that under high-flow conditions.

\section{CULVERT WITH V-NOTCHED SSW}

Two tests were conducted at different discharges for the $\mathrm{V}$-notched SSW. Fig. 7 shows the V-notched SSW and its upstream headcutting pattern. The minor headcutting for this model was not readily apparent. For these tests, the upstream bed stabilized at a higher elevation than the previous two sets of tests, resulting in increased sand bed thickness. The scour pattern developed with two triangles of a higher scour depth at the sides and less scour in the middle. Also, the depth of scour increased toward the ends of the SSW, and
FIG. 6 Model upstream flow and bed profiles of square notch with the ramp SSW: (a) low-flow and (b) high-flow.

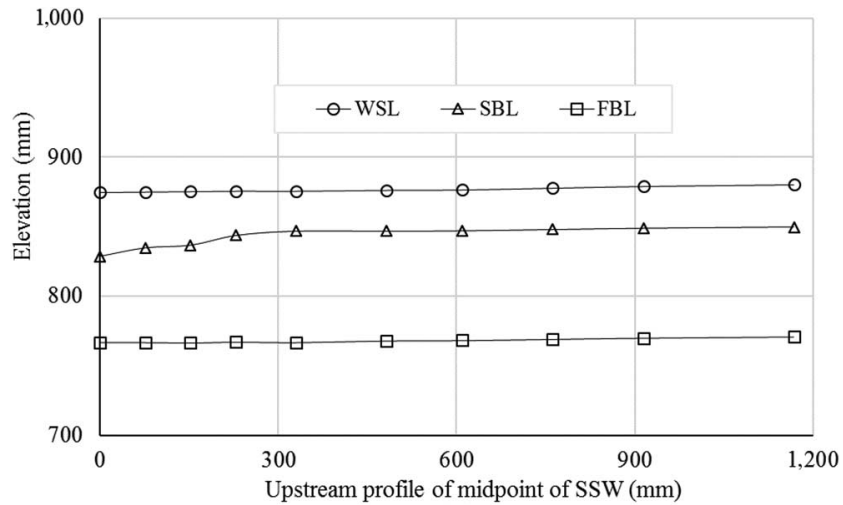

(a)

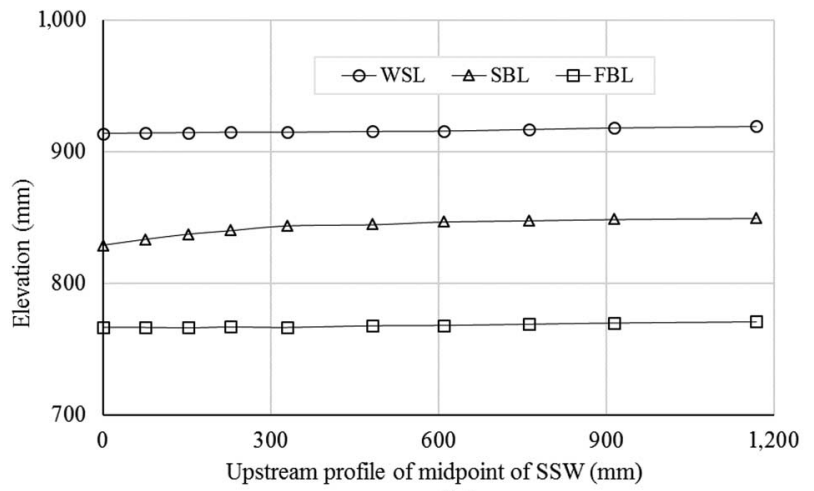

(b)

the depth was relatively shallow in the middle. An area of local scour existed at upstream of the $\mathrm{V}$-notch and extended a short distance into the minor scour region. A stable soil ramp was formed at the apron of the culvert at low-flow, which could assist AOP. Fig. 8 shows the flume bed, the sand bed, and the flow elevation profiles at upstream of the V-notched SSW wall.

At low-flow, the average depth was $23 \mathrm{~mm}$, and the flow velocity was $347 \mathrm{~mm} / \mathrm{s}$, which yielded a discharge of $0.002 \mathrm{~m}^{3} / \mathrm{s}$. At highflow, the average depth was $36 \mathrm{~mm}$ and the flow velocity was $354 \mathrm{~mm} / \mathrm{s}$, which yielded a discharge of $0.004 \mathrm{~m}^{3} / \mathrm{s}$. The difference in sand bed thickness was visually noticeable under low-flow and high-flow conditions. The extent of the headcutting at upstream during low-flow, as well as high-flow, was about $102 \mathrm{~mm}$ in the

\section{FIG. 5}

Culvert inlet with upstream incision due to the square notch with the ramp SSW.
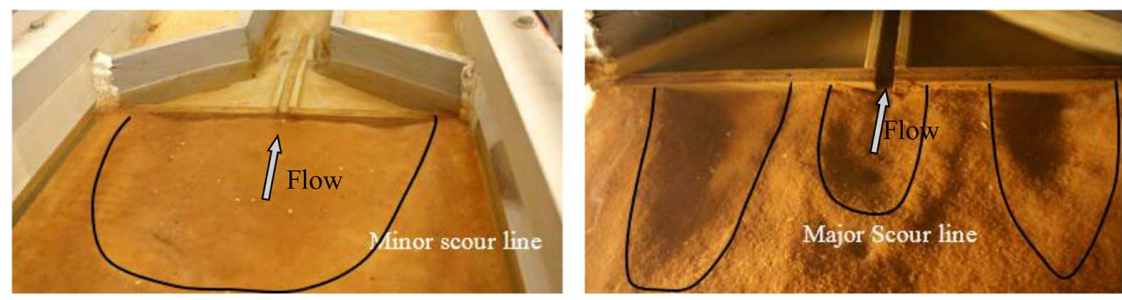
FIG. 7

Culvert inlet with upstream headcutting due to the V-notch SSW.
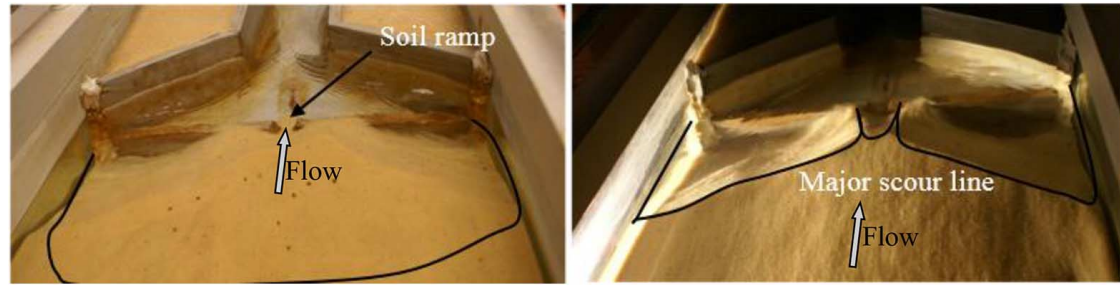

FIG. 8 Model upstream flow and bed profile of V-notched SSW: (a) low-flow and (b) high-flow.

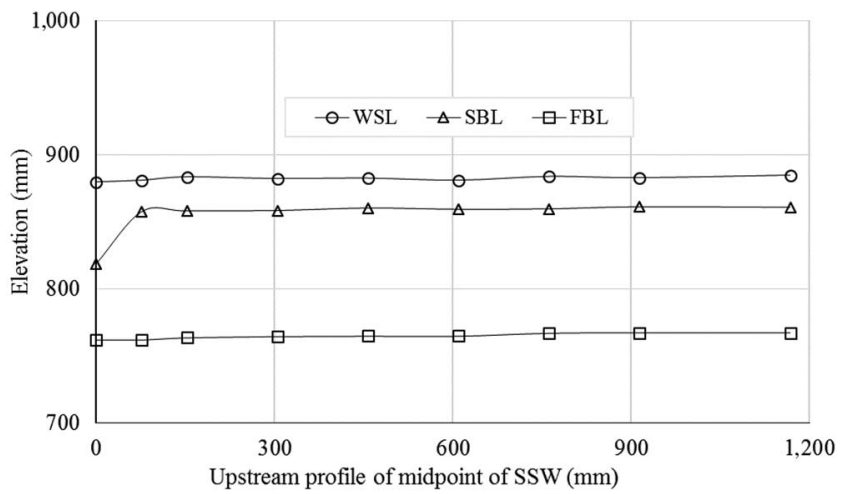

(a)

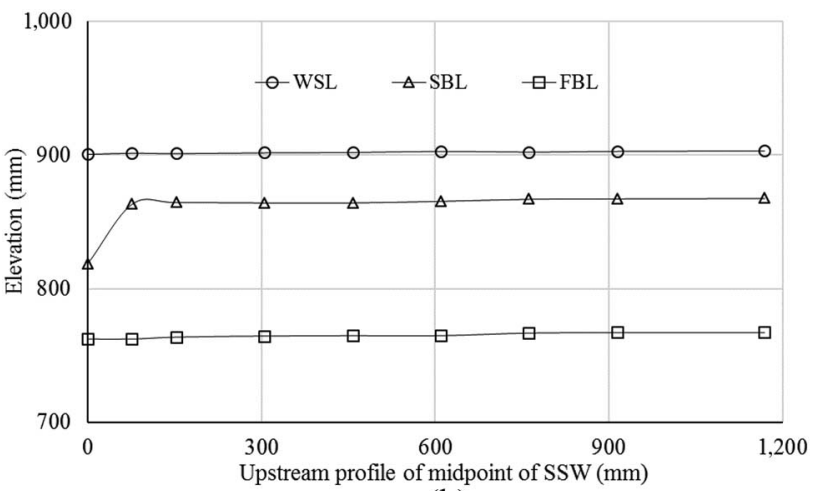

(b)

center, while the extent of headcutting was very large at the edge of the flume for both cases.

These flume tests showed that some bed scour occurred at upstream of the SSW. The shape and extent of headcutting were different for the solid and modified SSW. Limited scour was observed in the middle of the flume at upstream of all SSWs, and the amount of scour was greatest at approximately one-quarter distance from the sides of the flume for the solid and square notch SSW, and at the sides of the flume for the V-notched SSW. The effective areal extent of the scour was the highest for the solid SSW and the lowest for the V-notched SSW. Based on these observations, the inclusion of the $\mathrm{V}$-notch or square notch in the wall did not cause significant additional scour and would therefore not compromise the grade control mission of the SSW. Headcutting is not desirable at upstream of SSW. However, the local scour observed at upstream of the notch could assist to improve AOP at low flow by providing a gradual transition for a passage.

\section{Conclusions}

Many DOTs in the United States prefer to use a SSW-type inlet structure at upstream of the RCB culvert to prevent headcutting. These structures have different forms, such as vertical concrete walls, a gabion wall used as an upstream weir, and stone masonry upstream walls. Because of the regulatory issues regarding AOP, existing SSWs may have to be modified in a manner that helps preserve threatened and endangered species. Some states have been using notched SSW structures to facilitate the AOP. Based on the survey, states generally have been moving to modified grade control structure designs or alternative designs to facilitate AOP.

Fifteen site visits were carried out in Kansas to determine the existing conditions of SSW and headcutting. All of the SSW s were functioning well by controlling the grade as they retained the upstream soil, and there was little to no local scour. Moreover, the hydraulic efficiency was justified by the SSW as it controlled the flow upstream.

The flume study showed that scouring at upstream of the culverts with the solid SSW and the modified SSW in a sand channel bed was noticeable. All test sections apparently showed major and minor scour lines at upstream. The location of the maximum scour occurred immediately at upstream of the wall for all types of SSW, although the locations of the maximum scour along the SSW varied. From these tests, it was observed that at high-flow, headcutting was higher and deeper near the SSW than that at lowflow. For the V-notched and square notch flume tests, local scour was observed due to the notch; however, this scour was minor when compared with the overall upstream incision. While the $\mathrm{V}$-notch resulted in slightly deeper scour at high-flow, it also formed a soil ramp on the apron of the culvert under the lowflow conditions, which appeared to be more favorable for AOP. Based on the model performance, it can be concluded that the proposed V-notch and the square notch SSW modifications would reduce the potential barrier to AOP and pose minimal risk for causing significant additional headcutting. 


\section{ACKNOWLEDGMENTS}

The authors thank the Kansas Department of Transportation for providing financial support for this research. The authors also thank Matthew Maksimowicz, Zachary Aaron Brady, and Ghaith M. Salih Abdulrasool for providing technical support and field survey assistance for this research. Their participation is greatly appreciated.

\section{References}

[1] Kosicki, K. and Bennett, D. M., 2001, "A Summary of Alternatives to Conventional Culvert Pipe for Forest Roads," Forest Engineering Research Institute of Canada Western Division.

[2] Jackson, S. D., "Design and Construction of Aquatic Organism Passage at Road-Stream Crossings: Ecological Considerations in the Design of River and Stream Crossings," presented at the International Conference of Ecology and Transportation, Lake Placid, NY, Aug. 24-29, 2003, New York State Department of Transportation, Albany, NY, pp. 20-29.

[3] Kozarek, J. and Mielke, S., Sediment Transport Through Recessed Culverts: Laboratory Experiments, Final Report 2015-08, Minnesota Department of Transportation, St. Paul, MN, 2015, 106p.

[4] Kilgore, R. T., Bergendahl, B. S., and Hotchkiss, R. H., Culvert Design for Aquatic Organism Passage, Report No. FHWA-HIF11-008 HEC-26, Department of Transportation, Central Federal Lands Highway Division, Lakewood, CO, 2010, 234p.

[5] Bouska, W. W., Keane, T., and Paukert, C., P., "The Effects of Road Crossings on Prairie Stream Habitat and Function," J. Freshwater Ecol., Vol. 25, No. 4, 2010, pp. 499-506, https:// doi.org/10.1080/02705060.2010.9664398

[6] Fahrig, L. and Merriam, G., "Habitat Patch Connectivity and Population Survival," Ecology, Vol. 66, No. 6, 1985, pp. 1762-1768, https://doi.org/10.2307/2937372

[7] Datry, T., Bonada, N., and Boulton, A., Eds., Intermittent Rivers and Ephemeral Streams: Ecology and Management, Elsevier Science and Technology Books, Amsterdam, Netherlands, 2017, pp. 273-322.

[8] McEnroe, B. M., Lurtz, M. R., Parsons, R., L., and Neupane., M., Guidelines for Replacement of Deficient Bridges with Low-Water Stream Crossings in the Rural Midwest, Report No. FHWA-KS-16-19, Kansas Department of Transportation, Topeka, KS, 2017, 104p.

[9] Kansas Department of Transportation, KDOT Design Manual: Volume III - Bridge Section, Kansas Department of Transportation, Topeka, KS, 2015, pp. 12-54.

[10] Massachusetts Department of Transportation Highway Division, "Design of Bridges and Culverts for Wildlife Passage at Freshwater Streams," Massachusetts Department of Transportation, Boston, MA, 2010, 294p.

[11] California Dept. of Fish and Game, "Culvert Criteria for Fish Passage,” http://web.archive.org/web/20170613120249/ https://www.fs.fed.us/biology/nsaec/fishxing/fplibrary/CDFG_ 2002_Culvert_Criteria_for_Fish_Passage.pdf (accessed 13 June 2017)

[12] Forest Service Stream-Simulation Working Group, Stream Simulation: An Ecological Approach to Providing Passage for Aquatic Organisms at Road-Stream Crossings, National Technology and Development Program, San Dimas, CA, 2008, pp. B-3-5.

[13] Castro., J., "Geomorphologic Impacts of Culvert Replacement and Removal: Avoiding Channel Incision," U.S. Fish and Wildlife Service, Portland, OR, 2003, pp. 1-19.

[14] Johnson, P. A. and Brown, E. R., "Stream Assessment for Multicell Culvert Use,” J. Hydraul. Eng., Vol. 126, No. 5, 2000, pp. 381-386, https://doi.org/10.1061/(ASCE)07339429(2000)126:5(381)

[15] Bates, K., Barnard, B., Heiner, B., Klavas, P., and Powers, P. D., "Design of Road Culverts for Fish Passage," Washington Department of Fish and Wildlife, Olympia, WA, 2003, 112p.

[16] NRCS Conservation Practice Standard Code 578, Natural Resources Conservation Services, Washington, DC, 2011, www.nrcs.usda.gov

[17] McKinley, W. R. and Webb, R. D., "A Proposed Correction of Migratory Fish Problems at Box Culverts," Fish. Res., Vol. 1, No. 4, 1956, pp. 33-45.

[18] Engel, P., "Fish Passage Facilities for Culverts of the Mackenzie Highway," National Water Research Institute, Burlington, Ontario, Canada, 1974, 66p.

[19] Watts, F. J., "Design of Culvert Fishways," Idaho Water Resources Research Institute, Moscow, ID, 1974, 69p.

[20] Rajaratnam, N. and Katopodis, C., "Hydraulics of Culvert Fishways III: Weir Baffle Culvert Fishways," Can. J. Civ. Eng., Vol. 17, No. 4, 1990, pp. 558-568, https://doi.org/10.1139/ 190-064

[21] Rajaratnam, N., Katopodis, C., and McQuitty, N., "Hydraulics of Culvert Fishways II: Slotted-Weir Culvert Fishways," Can. J. Civ. Eng., Vol. 16, No. 3, 1989, pp. 375-383, https://doi.org/ 10.1139/189-061

[22] Kansas Department of Wildlife, Parks, and Tourism, "Threatened and Endangered Species Action Permit," http://web.archive.org/web/20160703173948/http://ksoutdoors. com:80/Services/Threatened-and-Endangered-Wildlife/ Threatened-and-Endangered-Species-Action-Permit (accessed 3 July 2016).

[23] U.S. Army Corps of Engineers, "Nationwide Permit," http:// web.archive.org/web/20160617164802/http://www.usace.army. mil/Missions/Civil-Works/Regulatory-Program-and-Permits/ Nationwide-Permits/ (accessed 17 June 2016).

[24] Haslouer, S. G., Eberle, M. E., Edds, D. R., Gido, K. B., Mammoliti, C. S., Triplett, J. R., Collins, J., Distler, D. A., Huggins, D., and Stark, W. J., "Current Status of Native Fish Species in Kansas," Trans. Kansas Acad. Sci., Vol. 108, Nos. 1-2, 2005, pp. 32-46, https://doi.org/10.1660/00228443(2005)108[0032:CSONFS]2.0.CO;2

[25] Kansas Department of Wildlife, Parks, and Tourism, "Kansas Department of Wildlife, Parks and Tourism: Threatened and Endangered Species," http://web.archive.org/ web/20160712052119/http://ksoutdoors.com:80/Services/ Threatened-and-Endangered-Wildlife (accessed 12 July 2016).

[26] Bowers, N., "Kansas Fish Passage Guide: A Guide for Constructing Stream Crossings on Local Roads and Private Drives to Provide for Fish Passage," Kansas University Transportation Center, Lawrence, KS, 2015, pp. 1-17.

[27] Jeppson, R., Open Channel Flow: Numerical Methods and Computer Applications, CRC Press, Taylor \& Francis Group, Boca Raton, FL, 1258p. 